\title{
Quality of Life in Patients Under Investigation for Unclear Chest Pain; Before and After Coronary Angiography
}

\section{Catrin Henriksson* Theresa Hallberg and Nina Johnston}

Department of Medical Sciences, Uppsala Clinical Research Center, Uppsala University, Sweden

\begin{abstract}
Background: Patients with unclear chest pain experience more anxiety compared to those receiving a clear diagnosis, and they also report lower quality of life (QoL) than a general population. The aim was to investigate if there were differences in QoL before coronary angiography compared to six months later.

Methods: This was a quantitative study using the questionnaire EQ-5D. The study population consisted of patients $(\mathrm{N}=150)$ with unclear chest pain, referred for elective coronary angiography. They were asked to complete a questionnaire the day before coronary angiography and six months later.

Results: Significant improvements were seen regarding usual activities, pain/discomfort and total health status on the day before coronary angiography compared to at six months follow up.

Conclusions: Patients with unclear chest pain seem to estimate their total health status before coronary angiography worse than both the general population and myocardial infarction patients. Those with coronary artery disease CAD rated better total health status in comparison to those with a final diagnosis of no CAD. However, six months later significant improvements were seen.
\end{abstract}

Keywords: Quality of life; Unexplained chest pain; Anxiety; Depression

\section{Introduction}

Chest pain is a common reason for seeking medical evaluation. In Sweden approximately 3000 men and women undergo coronary angiography each year due to unclear chest pain [1]. Diagnostic workup prior to coronary angiography often takes several months, and some patients are put on sick-leave [2]. Patients with unclear chest pain are known to have higher levels of anxiety in comparison to those with a determined cause of chest pain [3]. It is also known that both anxiety and depression increases the risk of cardiovascular morbidity and mortality [4-6], while decreasing quality of life (QoL) [7,8].

Patients living with unclear chest pain [9], as well as myocardial infarction (MI) patients, report lower QoL than the general population [10]. However, for both MI patients [11] and those receiving percutaneous coronary intervention (PCI) QoL improves over time [12]. Whether there is a similar trend for patients with unclear chest pain is less well known. The purpose of this study was to compare QoL in patients with unclear chest pain before and six months after coronary angiography.

\section{Methods}

\section{Design} design

This was a quantitative study with a descriptive and comparative

\section{Study population}

Patients with unclear stable chest pain referred for first-time elective coronary angiography were included $(\mathrm{N}=150)$. All patients were referred for this investigation due to a high suspicion of angina and a non-invasive test suggestive of CAD. The definition of CAD in our study was significant atheromatous at coronary angiography. None of the patients had any previous diagnosis of heart disease (i.e. MI, heart failure, valvular disease or arrhythmias). Patients were recruited from two Swedish hospitals, one university hospital and one county hospital. The patients were consecutively recruited from the coronary angiography waiting list for both hospitals during the period 20102013.

\section{Procedure}

Patients were included at admission, prior to coronary angiography. Written informed consent was required for participation. Patient data was obtained from medical records (co-morbidities) and a questionnaire. The questionnaire included questions about background characteristics such as educational level, smoking status and prior or current diseases. Patients were also asked to specify the duration of their symptoms (i.e. $<1$ month, 1-5 months, 6-11 months and $>12$ months). Chest pain was classified according to the Canadian Cardiovascular Society (CCS) criteria and also as typical, atypical and non-anginal chest pain as classified in the European Society of Cardiology guidelines for stable angina [13].

The primary discharge diagnosis was obtained from the patient's discharge summary and sub-classified into CAD, all I-20 international classification of disease [ICD] codes, and no CAD (all other diagnoses). At follow-up, six months after discharge, a telephone interview was conducted by research nurses. The patients were asked questions about

*Corresponding author: Catrin Henriksson, Department of Medical Sciences, Uppsala University, Uppsala, Sweden, Tel: +46 18 6110987; E-mail: catrin.henriksson@medsci.uu.se

Received November 09, 2015; Accepted November 29, 2015; Published November 30, 2015

Citation: Henriksson C, Hallberg T, Johnston N (2015) Quality of Life in Patients Under Investigation for Unclear Chest Pain; Before and After Coronary Angiography J Cardiovasc Dis Diagn 3: 230. doi:10.4172/2329-9517.1000230

Copyright: (C) 2015 Henriksson C, et al. This is an open-access article distributed under the terms of the Creative Commons Attribution License, which permits unrestricted use, distribution, and reproduction in any medium, provided the original author and source are credited. 
symptoms, further diagnosis, number of follow-up visits at medical facilities, sick leave, rehospitalizations, medications and EuroQol 5 dimensions (EQ-5D) questionnaire [14].

All patients with CAD, at coronary angiography, received at discharge guideline recommended medical treatment (i.e statins, platelet inhibitors, nitroglycerin, blood pressure lowering treatment) unless contraindicated.

\section{Quality of life questionnaire}

QoL was assessed using the questionnaire EQ-5D. The questionnaire was developed by the EuroQol group [14] to measure health outcomes and includes five dimensions: mobility, self-care, usual activities, pain/ discomfort and anxiety/depression. For each of the five dimensions, there are three levels of answers: no problems, some problems, extreme problems.

In relation to the dimension Anxiety/depression, patients were instructed to assess their level of anxiety with regard to regular daily life and not specifically relating to the coronary angiography procedure.

For assessing the patient's total health status, the questionnaire also includes a vertical scale (EQ-VAS), with the end-points best imaginable health state and worst imaginable health state. The patients marked the number on the scale that best agreed with their perceived overall health status.

\section{Statistics}

All statistical analysis was performed using the Statistical Package for the Social Sciences (SPSS) Version 21. The results were presented as numbers and percentages, median and mean values, i.e. for Background characteristics. For tests of differences between groups, we used the Chi square test for categorical variables (including the EQ-index variables) and the Mann-Whitney $U$ for the VAS-scale. The Sign test was used to examine differences between baseline (before coronary angiography) and 6-month follow up regarding to the EQ-index variables. No index tariff system was used regarding the EQ-index.

The Wilcoxon test was used for paired comparisons of the VASscale between baseline and 6-month follow up. A p-value of 0.05 or less was considered significant. There were no missing data in patient characteristics except for one patient regarding smoking status. Fourteen patients were lost to follow-up at six months.

The study protocol conforms to the Declaration of Helsinki and was approved by the Regional Medical Ethics Committee in Uppsala, Sweden.

\section{Results}

\section{Background characteristics}

In total, 150 patients with unclear chest pain were included in the study, whereof $66 \%$ men and $34 \%$ women. The median age for the total population was 64 years (women=63, men=64). Fifty-seven percent of the patients had an education level of more than nine years, $8 \%$ were current smokers, $41 \%$ ex-smokers and $49 \%$ had never smoked. Sixty-five percent of the patients had hypertension, $13 \%$ diabetes, $59 \%$ hyperlipidemia and $11 \%$ had a previous diagnosis of depression. Baseline characteristics for the population according to the diagnosis of CAD $(n=92)$ or no CAD $(n=58)$ are given in Table 1.

\section{Symptoms}

There were $51 \%$ of the patients with typical angina, $33 \%$ atypical angina and $16 \%$ non-anginal chest pain. More than half of the patients (59\%) had a symptom duration of more than six months.

\section{Discharge diagnosis}

The most frequent discharge diagnosis was angina pectoris, I.20 (61\%), and unclear chest pain, R07.4 (33\%).

\section{Total health status (EQ-VAS)}

At six month follow-up, the study population had an improved median EQ-VAS compared to before coronary angiography (75 vs. 70 , respectively, $\mathrm{p}=0.001)$. Women assessed their total health status at admission as worse than men, a significant difference $(\mathrm{p}=0.05)$, but six months later the difference was no longer significant $(\mathrm{p}=0.67)$. No differences were found in the typicality of symptoms with respect to EQ-VAS $(p=0.50)$. Patients with a final diagnosis of CAD rated their total health status at admission (EQ-VAS 82) as better than patients with no CAD did (EQ-VAS 66, $\mathrm{p}=0.03$ ); however, at six month followup no significant difference was observed (EQ-VAS 68 vs $66, \mathrm{p}=0.76$ ) (Figure 1).

\section{EQ-index}

EQ-index comparisons at admission and at six month follow-up are presented in Table 2. At admission, 79\% of the patients had no problems with mobility, no patients had problems with self-care, and

Table 1: Background characteristics according to CAD/No CAD.

\begin{tabular}{|c|c|c|c|c|}
\hline Characteristics & $\begin{array}{c}\text { Total population } \\
\mathbf{N = 1 5 0}\end{array}$ & $\begin{array}{c}\text { CAD } \\
\mathbf{N = 9 2}\end{array}$ & $\begin{array}{c}\text { No CAD } \\
\mathbf{N = 5 8}\end{array}$ & P-value \\
\hline Age, median (range) & $64(45-83)$ & $65(45-83)$ & $62(47-83)$ & 0.21 \\
\hline Gender (Women) \% & 34 & 43 & 57 & $\mathbf{0 . 0 0 1}$ \\
\hline Education >9 years \% & 57 & 65 & 35 & 0.53 \\
\hline Hypertension \% & 65 & 67 & 33 & $\mathbf{0 . 0 5}$ \\
\hline Diabetes \% & 13 & 7 & 3 & 0.39 \\
\hline Hyperlipidemia \% & 59 & 59 & 41 & 0.59 \\
\hline Prior depression \% & 11 & 5 & 5 & 0.32 \\
\hline
\end{tabular}

Chi Square test: $P$-value $<0.05$ indicates statistical significance.

Figure 1: EQ-VAS by diagnosis, before coronary angiography and at 6-months follow up.

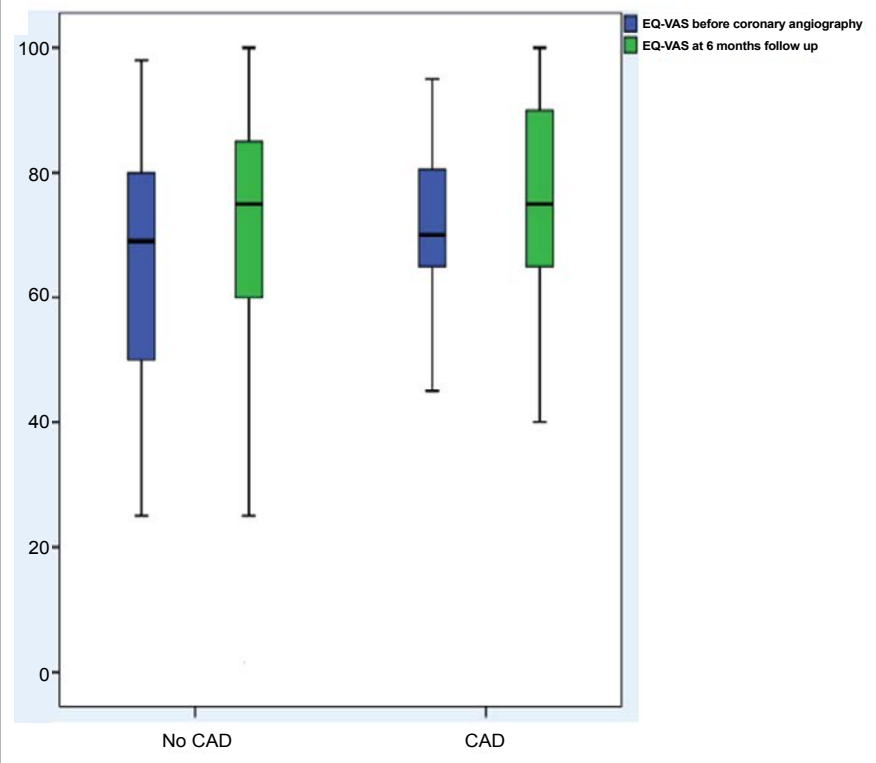


Table 2: EQ-index before coronary angiography $(\mathrm{N}=150)$ vs at six month follow-up $(\mathrm{N}=136)$.

\begin{tabular}{|c|c|c|c|c|}
\hline Variable & $\begin{array}{c}\text { No problems } \\
\text { Admission/6 } \\
\text { month }\end{array}$ & $\begin{array}{c}\text { Some } \\
\text { problems } \\
\text { Admission/6 } \\
\text { month }\end{array}$ & $\begin{array}{c}\text { Extreme } \\
\text { problems } \\
\text { Admission/6 } \\
\text { month }\end{array}$ & P-value \\
\hline Mobility \% & $79 / 79$ & $21 / 11$ & $0 / 0$ & 0.12 \\
\hline Self-care \% & $100 / 89$ & $1 / 2$ & $0 / 0$ & 0.50 \\
\hline Usual activities \% & $72 / 78$ & $28 / 10$ & $0 / 2$ & $\mathbf{0 . 0 0 2}$ \\
\hline Pain/discomfort \% & $27 / 48$ & $70 / 37$ & $3 / 5$ & $<\mathbf{0 . 0 0 1}$ \\
\hline Anxiety/depression \% & $65 / 63$ & $31 / 24$ & $3 / 3$ & 0.45 \\
\hline
\end{tabular}

Sign test: P-value $<0.05$ indicates statistical significance.

$72 \%$ perceived they had no problems with usual activities. $22 \%$ had no pain/discomfort, and $65 \%$ perceived no anxiety/depression.

No differences were found with regard to gender and EQ-index, nor were differences found between $\mathrm{CAD}$ patients and no $\mathrm{CAD}$ patients (Tables $3 \mathrm{~A}$ and $3 \mathrm{~B}$ ).

At six month follow-up, significant improvements were noted for the dimensions usual activities $(\mathrm{p}=0.003)$ and pain/discomfort $(\mathrm{p}<0.001)$ in the total population.

\section{Discussion}

The main findings from our study were the improvement over six months in total health status, usual activities and pain/discomfort in the total population. These results may reflect the benefits of coronary revascularization.

The total health status at admission in patients who received a diagnosis of no CAD was worse than for those who received a CAD diagnosis. Patients experiencing chest pain with no CAD diagnosis may be more anxious for a longer period of time and these feelings of anxiety may influence their daily life [15] and also QoL [16] negatively, emphasizing the importance of patients receiving a clear diagnosis. The group of patients with no CAD is at risk for re-hospitalization due to an unclear diagnosis to refer and relate to [16].

The majority of patients in our study population had a symptom duration of more than six months. This finding highlights the need for more expeditious medical evaluation of these patients.

\section{Total health status (EQ-VAS)}

When comparing the total health status of our study populations to that of the general population [17] or patients with confirmed CAD [18], VAS was lower. This result concurs with previous investigations showing that both physical and mental health were lower in a group of patients waiting for coronary angiograph [19]. However, at six month follow-up VAS ratings were improved, but still lower than those perceived by the general population and CAD patients.

In patients with unclear chest pain, the low EQ-VAS at admission might reflect anxiety regarding the underlying cause of the chest pain symptoms. However, patient education provided by a specialist nurse is shown to decrease anxiety during the waiting time before coronary angiography [20].

\section{EQ-index}

The majority of the patients reported few problems with mobility, self-care, usual activities or anxiety/depression, at admission and six months later. This may be explained by the relatively low age of our population and exclusion criteria (i.e. no previous heart disease).
Anxiety/depression was one of the dimensions with the least improvement at six months follow-up. At inclusion, 11\% of patients reported previous bouts of depression. Although this may factor explain our finding, previous studies support the finding that patients with unclear chest pain have more symptoms of depression and anxiety compared to the general population. Although CAD has been excluded, anxiety may persist in these patients due to a continued lack of knowledge as to the actual cause of symptoms.

\section{Method discussion}

The EQ-5D questionnaire is rapid and easily understood, and has been validated and found to be reliable for various diseases. However, it is not disease-specific and is not sensitive enough to measure the five dimensions in detail.

Although the questionnaire was completed prior to coronary angiography, we are not able to assess the extent to which patients' possible anxiety regarding the investigation might affect their level of perceived anxiety/depression. We must also keep in mind that all patients may not have had problems on the day they completed the questionnaire, but may usually have problems in their daily life. EQindex and EQ-VAS are not completely comparable since EQ-index was developed to reflect health status based on the general population, whereas EQ-VAS is a self-assessment of the subject's individual state of health. This might explain some differences in the findings between EQ-index and EQ-VAS. Another limitation of the study was a lack of data on patients not included in the study.

\section{Conclusions}

Patients with unclear chest pain seem to rate their total health status as worse than both the general population and MI patients before coronary angiography. However, a significant improvement was seen over the six months of follow-up. Patients diagnosed with no CAD rated their overall health status as worse than did patients diagnosed with CAD. Treatment for CAD was a factor improving QoL in these patients.

Usual activities and pain/discomfort were significantly improved during the follow-up period, whereas no significant improvement was seen for anxiety/depression.

Table 3A: EQ-index before coronary angiography, $C A D(N=92)$ vs No $C A D(N=58)$.

\begin{tabular}{|c|c|c|c|c|}
\hline EQ-index & $\begin{array}{c}\text { No problems } \\
\text { CAD/No CAD }\end{array}$ & $\begin{array}{c}\text { Some } \\
\text { problems } \\
\text { CAD/No CAD }\end{array}$ & $\begin{array}{c}\text { Extreme } \\
\text { problems } \\
\text { CAD/No CAD }\end{array}$ & P-value \\
\hline Mobility \% & $65 / 34$ & $45 / 55$ & $0 / 0$ & $\mathbf{0 . 0 4}$ \\
\hline Self-care \% & $61 / 39$ & $0 / 0$ & $0 / 0$ & - \\
\hline Usual activities \% & $63 / 37$ & $57 / 43$ & $0 / 0$ & 0.51 \\
\hline Pain/discomfort \% & $68 / 32$ & $60 / 40$ & $40 / 60$ & 0.43 \\
\hline Anxiety/depression \% & $65 / 35$ & $55 / 45$ & $40 / 60$ & 0.31 \\
\hline
\end{tabular}

Table 3B: EQ-index six months after coronary angiography, $\mathrm{CAD}(\mathrm{N}=82)$ vs No CAD $(\mathrm{N}=54)$.

\begin{tabular}{|c|c|c|c|c|}
\hline EQ-index & $\begin{array}{c}\text { No problems } \\
\text { CAD/No CAD }\end{array}$ & $\begin{array}{c}\text { Some } \\
\text { problems } \\
\text { CAD/No CAD }\end{array}$ & $\begin{array}{c}\text { Extreme } \\
\text { problems } \\
\text { CAD/No CAD }\end{array}$ & P-value \\
\hline Mobility \% & $61 / 39$ & $53 / 47$ & $0 / 0$ & 0.51 \\
\hline Self-care \% & $61 / 39$ & $0 / 100$ & $0 / 0$ & 0.08 \\
\hline Usual activities \% & $59 / 41$ & $67 / 33$ & $67 / 33$ & 0.84 \\
\hline Pain/discomfort \% & $68 / 32$ & $54 / 46$ & $37 / 63$ & 0.10 \\
\hline Anxiety/depression \% & $61 / 39$ & $53 / 47$ & $100 / 0$ & 0.10 \\
\hline
\end{tabular}

Chi Square test: $\mathrm{P}$-value $<0.05$ indicates statistical significance. 
Citation: Henriksson C, Hallberg T, Johnston N (2015) Quality of Life in Patients Under Investigation for Unclear Chest Pain; Before and After Coronary Angiography. J Cardiovasc Dis Diagn 3: 230. doi:10.4172/2329-9517.1000230

Larger studies are needed to confirm these findings as well as the health-economic consequences associated with worse quality of life in this large patient group.

\section{Implications for practice}

In patients with chest pain suggestive of CAD, QoL is affected, especially in patients in whom CAD is excluded at coronary angiography. This group of patients needs further attention after discharge, perhaps by way of counselling and medical follow-up. Patients with significant stenosis were revascularized when indicated.

To check the patients Qol status, a short questionnaire containing QoL-questions would be helpful to use at the referral time.

Patients with unclear chest pain must have a more rapid path to coronary angiography. To decrease the time to coronary angiography, it is important to take a strict anamnesis for estimating the severity of symptoms. Both doctors and nurses have to provide clear information to patients and relatives about symptom origins, how to act with regard to symptoms, and diagnosis. This would help the patient to seek medical attention earlier, but the medical care system must also act faster.

\section{Acknowledgements}

We would like to thank Uppsala University for the grant support.

The authors report no relationships that could be construed as a conflict of interest.

\section{References}

1. www.ucr.uu.se/swedeheart. 2012

2. Mourad G, Alwin J, Stromberg A, Jaarsma T (2013) Societal costs of noncardiac chest pain compared with ischemic heart disease-a longitudinal study. BMC Health Serv Res 13: 403.

3. Webster R, Norman P, Goodacre S, Thompson A (2012) The prevalence and correlates of psychological outcomes in patients with acute non-cardiac chest pain: a systematic review. Emergency medicine journal : EMJ 29: 267-273.

4. Kubzansky LD, Kawachi I (2000) Going to the heart of the matter: do negative emotions cause coronary heart disease? Journal of psychosomatic research 48: 323-337

5. Lichtman JH, Froelicher ES, Blumenthal JA, Carney RM, Doering LV, et al (2014) Depression as a risk factor for poor prognosis among patients with acute coronary syndrome: systematic review and recommendations: a scientific statement from the American Heart Association. Circulation 129: 1350-1369.
6. Hare DL, Toukhsati SR, Johansson P Jaarsma T (2014) Depression and cardiovascular disease: a clinical review. Eur Heart J 35: 1365-1372.

7. de Jonge P, Spijkerman TA, van den Brink RH, Ormel J (2006) Depression after myocardial infarction is a risk factor for declining health related quality of life and increased disability and cardiac complaints at 12 months. Heart 92 32-39.

8. Parashar S, Rumsfeld JS, Spertus JA, Reid KJ, Wenger NK, et al. (2006) Time course of depression and outcome of myocardial infarction. Arch Intern Med 166: $2035-2043$

9. Eslick GD (2008) Health care seeking behaviors, psychological factors, and quality of life of noncardiac chest pain. Disease-a-month : DM 54: 604-612.

10. Brown N, Melville M, Gray D, Young T, Munro J, et al. (1999) Quality of life four years after acute myocardial infarction: short form 36 scores compared with a normal population. Heart 81: 352-358

11. Simpson E, Pilote L (2003) Quality of life after acute myocardial infarction: a systematic review. Can J Cardiol 19: 507-511.

12. Weintraub WS, Spertus JA, Kolm P, Maron DJ, Zhang Z, et al. (2008) Effect of $\mathrm{PCl}$ on quality of life in patients with stable coronary disease. The New England journal of medicine 359: 677-687

13. Task Force M, Montalescot G, Sechtem U, Achenbach S, Andreotti F, et al. (2013) ESC guidelines on the management of stable coronary artery disease: the Task Force on the management of stable coronary artery disease of the European Society of Cardiology. Eur Heart J 34: 2949-3003.

14. Rabin R, de Charro F (2001) EQ-SD: a measure of health status from the EuroQol Group. Ann Med 33: 337-343.

15. Jerlock M, Gaston-Johansson F, Danielson E (2005) Living with unexplained chest pain. Journal of clinical nursing 14: 956-964.

16. Phan A, Shufelt C, Merz CN (2009) Persistent chest pain and no obstructive coronary artery disease. Jama 301: 1468-1474.

17. Burstrom K, Johannesson M, Diderichsen F (2001) Swedish population health-related quality of life results using the EQ-5D. Quality of life research : an international journal of quality of life aspects of treatment, care and rehabilitation 10: 621-635.

18. Ellis JJ, Eagle KA, Kline-Rogers EM, Erickson SR (2005) Validation of the EQ-5D in patients with a history of acute coronary syndrome. Current medical research and opinion 21: 1209-1216.

19. Arthur HM, Smith KM, Natarajan MK (2008) Quality of life at referral predicts outcome of elective coronary artery angiogram. Int J Cardiol 126: 32-36.

20. Harkness K, Morrow L, Smith K, Kiczula M, Arthur HM (2003) The effect of early education on patient anxiety while waiting for elective cardiac catheterization. European journal of cardiovascular nursing : journal of the Working Group on Cardiovascular Nursing of the European Society of Cardiology 2: 113-121. 